\section{Edycaçäa

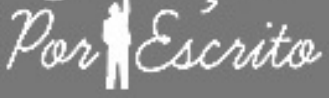

ARTIGO

\section{Editores}

Maria Inês Côrte Vitoria PUCRS, RS, Brasil

Pricila Kohls dos Santos PUCRS, RS, Brasil

\section{Equipe Editorial}

Rosa Maria Rigo

PUCRS, RS, Brasil

\title{
Formação e construção da identidade docente a partir da narrativa de histórias de vida
}

\author{
Formation and construction of teaching identity from the narrative of life's histories
}

\author{
Jussara Besuttia ${ }^{a}$ Roberta Cristina Redante ${ }^{\mathrm{b}}$, Altair Alberto Fávero ${ }^{\mathrm{c}}$
}

\section{RESUMO}

Este artigo objetiva compreender como as histórias de vida e as trajetórias de formação profissional contribuem para a construção da identidade de docentes na educação superior. A identidade de um professor deriva de aspectos como a sua história de vida, o significado que este atribui à docência, as suas práticas pedagógicas e a sua formação, que é, intrinsecamente, ligada à sua identidade e, ao mesmo tempo, vital para essa construção pessoal. Inicialmente, apresenta-se uma discussão teórica sobre aspectos do processo de formação docente e sobre a construção da identidade profissional. Na sequência, são apresentados os procedimentos metodológicos empregados na condução da pesquisa, bem como os resultados alcançados. O artigo responde à seguinte questão de pesquisa: como os docentes universitários constroem sua trajetória de vida e sua identidade? Participaram deste estudo empírico docentes de uma unidade acadêmica dos cursos de Administração, Contabilidade e Economia de uma universidade no RS. Os dados foram obtidos por meio das técnicas de pesquisa documental e de história de vida, de modo que a pesquisa pode ser caracterizada como de abordagem qualitativa. Como conclusão do estudo, destaca-se a ausência de preparação pedagógica no início da vida docente, pois constatouse que a área estudada não prepara adequadamente profissionais para a docência. Além disso, ressalta-se que as influências familiares e de professores marcantes determinaram sua trajetória e a construção da identidade, definindo suas vidas e sua formação como pessoas e profissionais.

Palavras-chave: Docência universitária; Formação docente; História de vida; Identidade.

a Possui graduação em Psicologia pela Universidade de Passo Fundo (2002). Pós graduação em Intervenções Psicossociais (UPF) e em Gestão de Pessoas (ESPM), formação complementar em Dinâmica dos Grupos, é Mestranda em Administração PPGAdm (UPF).

b Possui graduação em Design pela Universidade de Caxias do Sul (2015) e é Mestranda em Administração pela Universidade de Passo Fundo (UPF).

c Possui graduação em Filosofia Licenciatura Plena pela Universidade de Passo Fundo (1989), especialização em Epistemologia das Ciências Sociais (1993), mestrado em Filosofia pela Pontifícia Universidade Católica do Rio Grande do Sul (1998), doutorado em Educação pela Universidade Federal do Rio Grande do Sul (2007) e Pós-Doutorado (bolsista Capes) pela Universidad Autónoma del Estado de México (2012). Atualmente é professor titular III e pesquisador da Universidade de Passo Fundo. É professor do Corpo docente permanente do Mestrado e Doutorado em Educação atuando na linha de Políticas Educacionais. 


\section{ABSTRACT}

This article aims to understand how life histories and trajectories of professional formation contribute to the construction of the identity of teachers in higher education. The identity of a teacher derives from aspects such as his life history, the meaning he attributes to teaching, his pedagogical practices, and his formation, which is intrinsically linked to his identity and is vital to this personal construction. Initially, a theoretical discussion about aspects of the teacher formation process and the construction of the professional identity is presented, followed by the methodological procedures used to conduct the research and the results. The article sought to answer the following research question: How do university teachers construct their life trajectory and their identity? Participants of this empirical study were teachers of an academic unit of the courses of administration, accounting and economics of a university in RS. The data were obtained using documental research and life history techniques, being the aim of this research qualitative. As a conclusion of the study, we highlight the lack of pedagogical preparation at the beginning of the teaching life, since it was verified that the area studied does not adequately prepare professionals for teaching. In addition, it is emphasized that the influences of family and teachers were decisive in the trajectory and construction of identity, and mark their lives as people and professionals.

Keywords: University teaching; Teacher formation; Life's history; Identity.

\section{Introdução}

$\mathrm{O}$

atual contexto socio-histórico apresenta-se como complexo e carregado de desafios. Mas, de outro modo, esta época também traz consigo oportunidades decorrentes das novas tecnologias, do avanço das ciências, do progresso da técnica, da inovação das comunicações, da dinamicidade dos setores produtivos e das complexas relações de trabalho. No âmbito educacional, igualmente, encontram-se mudanças, desafios e oportunidades. Esse novo cenário é caracterizado pelas recentes oportunidades de acesso à escolarização, pela proliferação de instituições na educação superior, pelo aumento do número de vagas em todos os níveis de ensino, pelas mudanças sociais, pela heterogeneidade e pelos complexos problemas nas práticas docentes (FÁVERO e MARQUES, 2012). Contexto que traz desafios a serem superados para que a educação cumpra seu papel social, que se vincula à produção e à socialização do conhecimento, bem como ao estabelecimento de condições para que haja a promoção da cidadania.

Diante de tantos desafios, reconhece-se a importância do papel do docente na construção de uma educação que ofereça tais respostas à sociedade, de forma que o desenvolvimento pessoal e profissional dos educadores é fundamental para a superação das provocações percebidas. $O$ ensino superior e a discussão sobre a construção da 
identidade profissional de docentes universitários têm ganhado espaço em debates, pesquisas e teorizações sobre o tema. Conforme Fonseca (2002), as discussões acerca da identidade do docente universitário se intensificaram no Brasil, nos anos 1990, articuladas aos movimentos internacionais no campo da pesquisa em educação, de maneira que, nos dias atuais, ainda são permanentes a investigação e a reflexão nessa área.

Somam-se a isso vários fatores, como a história de vida, a formação inicial e continuada, o significado da docência para o professor e a prática pedagógica, conformando um conjunto que contribui para o desenvolvimento e construção da identidade profissional. Essa construção é profundamente impactada por condições objetivas e subjetivas que envolvem o trabalho do professor e a maneira como este o percebe em constante movimento (NUNES, 2013).

Diante do exposto, apresenta-se como questão norteadora desta pesquisa: como os docentes universitários constroem sua trajetória de vida e sua identidade? A investigação se justifica por se acreditar que as vivências dos professores, suas experiências pessoais e/ou profissionais, e os saberes que são mobilizados à medida que estes desenvolvem seu trabalho. articulam-se às histórias de vida e constituem processo de construção de identidade, impactando a vida dos acadêmicos, tanto como pessoas quanto como profissionais.

Assim, o objetivo deste trabalho é compreender como as histórias de vida e as trajetórias de formação profissional colaboram na construção da identidade de docentes no ensino superior. Realizou-se uma investigação de abordagem qualitativa e exploratória com docentes das áreas de Administração, Economia e Ciências Contábeis. Foram utilizadas como técnicas de coleta de dados as narrativas de histórias de vida e a pesquisa documental. Para análise e discussão dos resultados, seguiu-se a técnica de análise de conteúdo.

\section{0 processo de formação docente}

A educação superior, de modo especial na atualidade, tem sido afetada por crises econômicas, políticas, de sentidos e de valores. Isso ocorre em razão de sua responsabilidade em produzir e disseminar conhecimentos úteis ao desenvolvimento da economia global, dos seres humanos e da sociedade como um todo. Esse contexto sóciohistórico interfere no trabalho docente e nos sentidos de sua formação. E uma formação docente sólida, composta pela qualificação científica e pedagógica das diversas nuances que caracterizam a docência, é condição indispensável para a qualidade do ensino universitário (ZABALZA, 2004).

A formação de um indivíduo abrange o desenvolvimento pessoal do ser em todos os seus aspectos, desde conhecimentos e habilidades, até seus valores e significados (ZABALZA, 2004). Para Nóvoa (2000), ao se falar do processo de formação, está se falando, intrinsecamente, da construção da identidade de uma pessoa. A formação de um indivíduo está estreitamente relacionada à sua realização pessoal e profissional, indo muito além do período 
escolar e dos conteúdos de formação (ZABALZA, 2004). De acordo com Cardoso, Batista e Graça (2016, p. 382), "no plano subjetivo, a formação é entendida como um processo de apropriação pessoal e reflexiva, de integração da experiência de vida na experiência profissional, em função das quais a ação educativa adquire significado".

Parte-se do pressuposto de que a formação é constante, dinâmica e deve ser continuada. Contudo, uma grande parcela dos docentes do ensino superior não foi formada para ser educador, não dispõe dos saberes decorrentes da teoria pedagógica (RIBEIRO e CUNHA, 2010). Além disso, Tardif (2002) afirma que a formação profissional do docente universitário ocorre, continuamente, em diversas fases de trabalho que se alternam desde a formação escolar inicial (que também reflete a formação profissional); formação universitária inicial; ingresso na carreira docente (que pode ocorrer durante ou posteriormente à graduação); e formação que este desenvolve ao longo da vida profissional. O docente precisa apropriar-se de saberes científicos, mas os saberes pedagógicos são, igualmente, fundamentais para o exercício competente da docência, de tal modo que ambos os saberes são determinantes na formação de professores (VIOLA, 2007).

O docente, ao longo de sua história de vida pessoal, interioriza conhecimentos, competências, crenças e valores que estruturam a sua personalidade e as suas relações com os outros, podendo ser reatualizados e reutilizados. De fato, é nesse tempo que o "eu pessoa" no papel de professor vai desenrolando sua vida profissional e tornando-se um "eu profissional" (TARDIF e RAYMOND, 2000). A partir desse entendimento, a formação mobiliza diversos saberes, e estes produzem sentido à profissão docente. Contudo, não há uma linearidade desses saberes. Ser docente é compreender-se com conhecimento inacabado e reconhecer que isso envolve uma complexidade de valores que são constantemente modificados e estão dinamicamente envolvidos num diálogo contínuo com suas experiências práticas cotidianamente vivenciadas em seu contexto de trabalho (NUNES, 2013).

O ser humano ao longo de sua história se forma e se transforma em interação com outros (NÓVOA, 2007). Assim, compreender como uma pessoa, em especial o professor, formou-se é encontrar relações entre a pluralidade de suas trocas e vivências internas ou externas nos diversos momentos de sua vida. Além disso, compreende-se que essa formação está diretamente relacionada à construção da identidade do ser professor e, portanto, de si mesmo, na qual o desenvolvimento dos significados e valores se transforma ao longo de toda a trajetória de formação pessoal e profissional.

\section{A construção da identidade profissional docente}

A construção da identidade profissional acontece ao longo de toda a vida do indivíduo, por meio da interação social com o outro e das influências internas e externas percebidas (CARDOSO, BATISTA e GRAÇA, 2016). A identidade do professor, segundo Nóvoa (2007, p. 16), não é um dado adquirido, uma propriedade ou um produto, mas 
é "um lugar de lutas e de conflitos, é um lugar de construção de maneiras de ser e de estar na profissão". Também é um processo longo e complexo que mescla o sentimento e o discurso de ser professor (NÓVOA, 2000). Esse processo identitário necessita de tempo, requer acomodar inovações, assimilar mudanças, (re)pensar a prática pedagógica num processo de autoconsciência sobre o que faz, como faz e por que faz em sala de aula, com os saberes (seus e de seus alunos). Desse modo, o eu pessoal e o eu profissional são indissociáveis (NÓVOA, 2000).

Segundo Catani, Bueno e Sousa (2000, p. 168), "abordar a identidade implica, necessariamente, falar do eu, bem como das formas pelas quais o sujeito rememora suas experiências e entra em contato consigo mesmo". Os autores afirmam ainda que "as memórias pessoalmente significantes são aquelas que carregam significados adquiridos em seus usos adaptativos, na maior parte das vezes, nas relações com os outros. Os outros são, dessa forma, referências imprescindíveis das nossas lembranças" (p. 168-169). De acordo com Pimenta (2002), a identidade profissional do professor é construída, dinâmica e constantemente, pelo significado que cada professor confere à sua atividade. Esse significado deriva dos seus valores, de seu modo de se situar no mundo, de sua história de vida, das representações, dos saberes, das angústias, dos desejos e, é claro, do sentido que tem em sua vida o fato de ser professor.

Essa afirmação também vai ao encontro dos escritos de Timm e Abrahão (2015), que afirmam ser a docência uma construção dinâmica, com uma diversidade de sentimentos, consciências, valores, significados e representações. Por estar em constante transformação, o processo de construção da identidade se reconstitui ao longo do tempo e é marcado pela maneira como o professor constrói sua imagem, por suas convicções, desejos e expectativas, por suas experiências, pela maneira como repensa suas práticas pedagógicas, e, ainda, por sua formação docente e função social (BURNIER et al., 2007).

Formar-se pressupõe troca, interações sociais e aprendizagem contínua, num processo pessoal e singular (NÓVOA, 2000). As construções da identidade pessoal e da profissional não estão dissociadas. Assim, esta resulta das relações tecidas consigo e com o social, entre o eu e o outro. Tendo isso em mente, a construção da identidade do professor traz no seu escopo uma dimensão espaço-temporal. Essa construção atravessa toda a vida profissional desde a fase de escolha e decisão pela docência, a formação formal, os espaços institucionais nos quais sua atuação se desenrola. Logo, essa identidade reflete as marcas das experiências e escolhas, das práticas desenvolvidas, das ações continuadas de formação, da vida e da profissão docente de modo mesclado (NÓVOA, 2000).

\section{Método}

Visando a compreender como os docentes universitários constroem sua trajetória de vida e sua identidade, delineou-se esta pesquisa a partir de uma abordagem qualitativa do problema (RICHARDSON, 2012). Com relação 
aos objetivos da pesquisa, esta caracteriza-se como exploratória. As pesquisas exploratórias têm como finalidade esclarecer conceitos, convertendo o problema em algo mais explícito, com o objetivo de torná-lo mais familiar, além de possibilitar a consideração de diversos aspectos relacionados ao fenômeno de investigação (GIL, 2002).

A amostra selecionada foi composta por docentes que atuam em uma universidade comunitária do norte do estado do Rio Grande do Sul, na Unidade Acadêmica de Ciências Econômicas, Administrativas e Contábeis. Escolheu-se uma unidade que não estivesse ligada às licenciaturas, visando a compreender como ocorre a formação em áreas que não apresentam foco principal em práticas pedagógicas ou em questões relacionadas à didática. A seleção da amostra baseou-se no critério de tempo de atuação na profissão docente, e o tempo mínimo definido foi de dez anos, por acreditar que quanto maior o tempo de carreira, mais os docentes têm oportunidades de aperfeiçoar suas práticas. Outro critério utilizado para a seleção foi a diversidade de regimes de trabalho, como horista, de forma parcial ou com dedicação integral. Foram selecionados docentes dos três regimes, pois entende-se que essa diversidade possibilita percepções distintas sobre a profissão e sobre a universidade.

Primeiramente, os participantes foram contatados via e-mail, apresentando-se o propósito da pesquisa e indagando-se sobre o interesse voluntário destes em participar. Posteriormente, os participantes que demonstraram empenho receberam um contato telefônico agendando a entrevista. Dos 15 convidados, cinco docentes aceitaram participar e compuseram a amostra que contou com três doutores e dois mestres. Quatro do gênero masculino e um do gênero feminino. A média de tempo de atuação na docência entre eles é de 17 anos.

A coleta de dados ocorreu entre os meses de dezembro de 2016 e janeiro de 2017. Para levantamento dos dados, foram utilizados dois instrumentos de coleta: pesquisa documental e narrativa de história de vida. Na execução do trabalho, foram observados todos os procedimentos éticos referentes à pesquisa com seres humanos, incluindo a utilização do Termo de Consentimento Livre Esclarecido (TCLE). As entrevistas foram realizadas individualmente, gravadas e transcritas na íntegra. Depois da apresentação dos objetivos da pesquisa, leitura e assinatura do TCLE, foram realizadas as entrevistas por meio do método de história de vida, com duração de aproximadamente uma hora cada uma.

O método história de vida valoriza, metodologicamente, os conhecimentos sobre os indivíduos a partir da experiência humana, tal como esta é vivida e definida por seus próprios atores. Bem como possibilita ao pesquisador contatos com diferentes memórias, as quais se constituíram no desenvolvimento do indivíduo, tanto pessoal como profissionalmente, como também permitem ao sujeito o estabelecimento de um diálogo interior com seu próprio eu, tomando consciência sobre sua existência e compreendendo, assim, sua trajetória de vida (JOSSO, 1999).

Nas pesquisas em educação, a abordagem com história de vida vem crescendo e denota uma vigilante metodologia e um rigor teórico. Uma de suas principais potencialidades é o diálogo entre o individual e o sociocultural (NÓVOA, 
2000; BURNIER et al., 2007). Neste estudo, a história de vida é entendida como uma estratégia de pesquisa que integra a abordagem biográfica (DENZIN, 1989). Ao se compreender o relato da história de vida dos professores, entende-se a necessidade de se conhecer a trajetória pessoal que trilharam e os significados de docência construídos (BURNIER et al., 2007).

Durante as entrevistas, alguns professores se emocionaram ao recordar de fatos marcantes. Nesse contexto, os relatos das trajetórias de vida representaram não apenas uma contribuição para uma pesquisa científica, mas uma oportunidade de reflexão a respeito dos momentos marcantes, das conquistas, alegrias, tristezas e dificuldades vivenciadas por eles. Ao contar sua história de vida e trajetória, professores refletiam também sobre ela, modificavamse também como sujeitos sociais. A narrativa do professor 4 (P4) retrata significativamente tal afirmação:

"Então todos esses detalhes eu nunca tinha falado para ninguém. Eles estão marcados muito, muito fortes na minha vida. A ponto de eu saber datas... de eu saber horários, saber pontos de parada, enfim. Porque realmente foi... foi doloroso. Não diria trabalhoso. Mas foi doloroso todo esse processo para chegar até aqui. Mas faz parte. Hoje a gente só colhe os frutos desse processo todo, desse aprendizado todo. É muita gratificação." (P4)

A coleta das histórias de vida foi realizada com apoio de algumas questões para fomentar a narrativa dos participantes, que visou a abordar: construção da história pessoal e profissional; experiências mais impactantes; principais dificuldades da carreira docente; principais influências; questões sobre formação continuada; significado de ser docente; e realização enquanto tal.

Após realizada a etapa de coleta de dados das histórias de vida, efetivou-se uma pesquisa documental. De acordo com Cellard (2008), a análise documental auxilia os pesquisadores a entender a realidade social a partir da dimensão tempo e, também, a observar o processo de evolução de indivíduos, conhecimentos, práticas, entre outros. Para essa etapa da pesquisa, os dados foram levantados por meio da Plataforma Lattes. Ao analisar os currículos lattes dos docentes que compunham a amostra, objetivou-se mapear alguns de seus dados pessoais e profissionais, para, posteriormente, responder às seguintes perguntas: como se formaram os que hoje formam os professores e como desenvolvem e registram sua formação continuada?

Como método de análise dos dados, optou-se pela análise de conteúdo qualitativa de Bardin (2000). Esta contempla não só o conteúdo manifesto do material, como o próprio nome pode sugerir, mas, também, informações de contexto e conteúdo latente (BARDIN, 2000). O processo interpretativo de construção das categorias e subcategorias de análise teve início na realização das entrevistas em profundidade, passou pela transcrição destas, pela leitura 
aprofundada e pela identificação de categorias e de subcategorias que emergiram das narrativas de vida dos entrevistados. As categorias obtidas por esse processo subdividiram-se em formação docente, com as subcategorias decisão e escolha, dificuldades e formação continuada; e identidade docente, com as subcategorias influências, significado, reconhecimento e realização.

\section{Decisão, dificuldades e formação continuada}

Diante dos relatos das histórias de vida, alguns pontos principais foram marcantes ao longo das narrativas. Primeiramente, destacam-se os relatos sobre o início de suas trajetórias, processo de escolha da docência, dificuldades iniciais e sobre como constroem cotidianamente sua identidade profissional por meio das experiências de formação continuada.

No que tange à escolha pela docência universitária, a maioria dos entrevistados relatou ter tido desejo ou sonho de seguir um dia a profissão de professor. As escolhas e os caminhos tomados, conscientes ou não, foram direcionando-os para a docência universitária; os entrevistados transpareceram orgulho de suas decisões e escolhas. Essa afirmação encontra eco na narrativa que segue:

"Mas eu tracei uma trajetória de vida... foi o que eu tracei como trajetória de vida: um período só consultoria, um período mesclando os dois e um período final, no qual já estou, só universidade, só no magistério. Então foi uma trajetória que eu tracei e me considero bem-sucedido, atingi." (P2)

No início da prática docente, o significado da profissão e os valores e imagens atribuídos a essa prática podem se desconstruir em função do cotidiano de trabalho e se reconstruir por meio da percepção de novos significados e interações estabelecidos (CARDOSO, BATISTA e GRAÇA, 2016). Os depoimentos dos sujeitos pesquisados sobre suas primeiras experiências em sala de aula corroboram essa ideia na definição do que era adequado para suas práticas:

“[...] tive algumas dificuldades no sentido de controlar o ímpeto do mestrado no sentido de volume de disciplina, de conteúdo para repassar para os alunos da graduação. [...] E aí então eu comecei a mensurar qual seria a capacidade ideal para os alunos de conteúdo, de matéria, de atividades extraclasse e isso acabou dando certo. Essa foi a primeira dificuldade que eu encontrei." (P4)

A formação de um indivíduo não está vinculada apenas a uma fase de sua vida ou a uma instituição, mas, sim, é um percurso que se estende ao longo de sua vida e, por isso, necessita de estímulos e sistemas de apoio, 
com infraestrutura e oportunidades contínuas (ZABALZA, 2004). Contudo, por vezes, há a falta de um espaço especialmente criado para a formação pedagógica, sobretudo nos cursos de bacharelado, em que tal investimento fica a cargo dos próprios sujeitos interessados em seguir a carreira docente. Sobre isso, Pimenta (2002, p. 154) observa que "[...] a formação docente para o ensino superior ainda fica a cargo de iniciativas individuais e institucionais esparsas, que não se referem a um projeto nacional ou da categoria docente". Assim, esses profissionais devem apropriar-se, durante a prática profissional, dos saberes necessários para o exercício da docência superior.

Nas vozes dos participantes da pesquisa, evidenciou-se que a sua formação continuada advém principalmente da instituição de ensino onde atuam. A universidade incentiva e oferece oportunidades para os docentes realizarem cursos em diversas áreas, como, por exemplo, aperfeiçoamento didático. Um dos participantes (P5) destacou a importância dessa oferta, visto que áreas que não estão ligadas às licenciaturas carecem de formação complementar e que as formações sempre são experiências muito ricas. Essa visão é complementada por outro entrevistado: “[...] a gente não tá preparado para dar aula, né? O máximo que a gente tem no mestrado ou no doutorado é uma disciplina de preparação pedagógica, e isso sem dúvida alguma não é o suficiente para a gente ser um professor" (P4). Entretanto, ressalta-se também a importância de o docente buscar sua própria autoformação, pautada por uma reflexão sobre as suas práticas em sala de aula e sobre os seus saberes e (não) saberes, atuando, assim, como combustível na busca por caminhos para a qualificação da prática docente, sejam eles formais ou não (CONFORTIN, 2015).

O contexto escolar apresenta cenários cada vez mais dinâmicos, que exigem que o professor busque um aprimoramento tanto profissional quanto pessoal, no qual muitas respostas podem ser obtidas por meio da formação contínua (ZABALZA, 2004). As falas dos respondentes apontam para essa busca de atualização constante. Um deles (P5) relata que um desafio para o docente em sala de aula é não se acomodar, não estar na zona de conforto, sobretudo devido às mudanças contínuas que a tecnologia traz para o contexto escolar. Outra fala assevera:

"Mas a formação, ela tem que ser algo permanente, você não para de aprender, você não pode se permitir parar de aprender. E aprender não significa estar sentado em uma sala de aula quando você... você tem que ter a capacidade de na simples observação de alguma coisa aprender.” (P2)

Diante dos relatos dos sujeitos da pesquisa sobre a busca por formação constante, analisou-se o currículo dos participantes na Plataforma Lattes, na busca por compreender a evolução de suas trajetórias e esclarecer como os docentes desenvolvem sua formação. Com relação aos cursos de formação continuada, destaca-se o predomínio dos 
que são realizados na própria instituição na qual atuam, o que corrobora o relatado anteriormente. Os cursos que os docentes realizam fora da instituição são geralmente em temas específicos de suas áreas de pesquisa e atuação. Dos cursos internos da instituição, diversos buscam aperfeiçoar as práticas pedagógicas, em temáticas como didática e docência, o que demonstra uma preocupação da instituição pela qualificação de seu corpo docente. Porém, destaca-se uma falta de assiduidade na participação nesse tipo de formação. Conforme observado, não é uma prática contínua, nem mesmo anual.

Outro fator identificado nos currículos foi o espaçamento de tempo entre a conclusão e o início de novas formações acadêmicas. $\mathrm{Na}$ maioria dos relatos, identificou-se que as formações ocorreram concomitantemente à prática docente, o que pode ter dificultado a permanência e a continuidade dos estudos acadêmicos, devido à dedicação necessária para tal. Mas, ao mesmo tempo, os próprios docentes relataram que atuar como docentes os incentivou a continuarem se especializando. Além disso, observou-se uma grande participação em congressos e eventos acadêmicos relacionados à área de especialidade, em um nível superior ao encontrado nos cursos de formação. Essa participação está bastante relacionada à pesquisa, com a apresentação de trabalhos científicos, e ao estabelecimento de relações entre os participantes mais atuantes em cada área. Assim, à medida que o docente adquire experiência na profissão, em contato com as situações cotidianas, constrói-se um modo particular de lidar e ministrar aulas, arraigados nas práticas sociais coletivas da profissão docente (NUNES, 2013).

Uma questão que apareceu claramente na narrativa de vidas dos cinco participantes é a carência de formação pedagógica, principalmente no início da carreira. Essa lacuna desencadeou dificuldades, entre as quais as mais citadas foram a carência de leitura de turma e de relação professor-aluno, bem como o foco exacerbado na transmissão maciça de conteúdo. Não causa estranhamento o fato de o docente enfrentar, frequentemente, dificuldades para compreender e desenvolver sua profissão, que tem como exigência o domínio de diferentes saberes (NUNES, 2013). Uma das falas relata: "O sujeito chega lá verdinho do mestrado, chega rachando lenha e acelera de uma maneira... porque não tem experiência e não tá se tocando se a turma tá acompanhando..." (P5).

Pensar a formação de professores universitários é ir além dos saberes científicos e pedagógicos. É considerar o papel que esse profissional tem na sociedade (VIOLA, 2007). De certo modo, os docentes têm essa preocupação. O depoimento a seguir reflete tal citação:

"Cada turma é uma turma nova, novas demandas, e eu acredito que o nosso papel é entender as necessidades dos alunos aqui, (...) acho que nós acabamos sendo um pouco, se não um exemplo, uma referência, até por estarmos aqui tentando passar não só o conhecimento, mas nós somos pessoas facilitando, nós tentamos fazer com que o aluno pense, entenda, interaja, nosso papel... ele é muito importante.” (P5) 


\section{Influências}

A partir dos episódios de memória, podem-se perceber nítidas relações entre as experiências escolares e a formação da identidade do professor (QUADROS et al., 2005). Mesmo tendo claro que a fantasia e/ou idealização permeiam narrativas quando estas envolvem lembranças, memórias e recordações, pode-se considerar que a maneira como o passado é reconstruído pode representar como o entrevistado pretende que seja a sua vida (postura). A lembrança de alguns professores demonstra ser algo marcante e com forte influência na construção da identidade pessoal e profissional, como se observa pela narrativa a seguir:

\footnotetext{
"Ser professor é algo que a gente lembra dos bons professores, dos caras que marcaram a gente, né? E isso quando a gente era pequeno. Quando a gente tá na faculdade, quando a gente tá na pós, no mestrado, a gente lembra muitas vezes dessas pessoas porque havia um cuidado, independente da maneira, um maior cuidado conosco... tanto que nós marcamos, marcamos." (P5)
}

De acordo com Pimenta (2002), a identidade do docente é construída historicamente, por meio das características do sujeito, das experiências e das práticas sociais que, dinamicamente, constroem sua identidade como professor. Muitos são os motivos ou fatores que levam o docente universitário a escolher tal profissão. Contudo, para a amostra deste trabalho, as duas principais influências foram: os fatores familiares e a identificação com outros professores que impactaram suas vidas ao longo de sua trajetória educacional desde a escola primária até o doutorado.

Da amostra da pesquisa, destaca-se o papel representativo de familiares próximos no que a docência representa. Alguns participantes destacaram que o papel que seus pais, mães, tios e tias desempenharam no ensino, básico ou superior, influenciou suas escolhas profissionais. Um deles relata: "Se eu for te contar minha história aqui dentro da universidade, na verdade, a primeira vez que eu entrei na universidade foi em 1964, na barriga da minha mãe" (P3). Esse entrevistado tem diversos outros membros da família atuando como docentes, o que tornou o ambiente acadêmico algo natural para ele. Outra fala significativa relata também que, apesar de sempre criticar sua mãe e tias que eram professoras pelas falas constantes sobre os problemas escolares, e que, inicialmente, faziam-na pensar que nunca seria professora, ao afirmar "eu devo ter mordido várias vezes a minha língua ao longo do tempo" (P1), retrata que a influência familiar foi significativa ao aceitar a oportunidade de lecionar, e que a levou à docência universitária. 


\section{Significado}

A trajetória docente integra tanto a dimensão pessoal quanto a profissional. Sendo que a dimensão pessoal traz a perspectiva subjetiva do professor no decorrer do seu ciclo de vida, em que as marcas pessoais e da profissão se entrelaçam e interpenetram, mas mantêm sua especificidade própria. A dimensão profissional envolve os percursos dos professores em uma ou em várias instituições de ensino, nas quais estão ou estiveram atuando. É um processo complexo em que fases da vida e da profissão se entrecruzam, sendo únicas em muitos aspectos (BUSS, 2000).

Ainda, ao construir a trajetória, a identidade profissional do professor vai, também, sendo formada. Esse processo é dinâmico, constante e alicerçado nas vivências, nas trocas e no significado que cada professor confere à sua atividade. Esse significado deriva dos valores, de sua visão de mundo e da educação, de sua história de vida pessoal, das escolhas, das representações, dos aprendizados, das angústias, dos desejos e, é claro, do sentido que tem em sua vida o fato de ser professor (PIMENTA, 2002).

\section{Quadro 1. Significados de ser docente}

\begin{tabular}{|c|c|}
\hline Significado & Narrativas dos participantes da pesquisa \\
\hline $\begin{array}{l}\text { MAGIA, PALCO, } \\
\text { TRANSFORMAÇÃO }\end{array}$ & $\begin{array}{l}\text { "[...] parece que é uma mágica, sabe? Parece que é uma coisa assim ó, surreal. Eu to muito cansada, me arrastando no corredor, } \\
\text { mas quando eu piso na sala de aula, parece que é um palco, holofotes em mim, é uma coisa mágica, uma sensação muito, muito } \\
\text { joia." (P1). }\end{array}$ \\
\hline $\begin{array}{l}\text { RELAÇÃO PAI e FILHO, } \\
\text { PLANTIO, SEMENTES }\end{array}$ & $\begin{array}{l}\text { "Você não é as palavras que estão sendo ditas. Você, na frente de uma turma, é muito mais do que isso... a palavra que você diz você } \\
\text { poderia escrever, você poderia gravar um vídeo, videozinho, uma fita estaria resolvido. [...] Mas o conhecimento não é o professor } \\
\text { que transmite, é o aluno que constrói. [...] O que tu transmites é muito além: o teu exemplo de vida, a tua forma de ser, a tua forma } \\
\text { de batalhar essas coisas todas assim, a capacidade de observar coisas... então tudo isso vai contribuindo para a formação. [...] Então } \\
\text { você tem várias formas de transmitir vida, suas vivências, mas nisso o papel dessa interação professor-aluno é fundamental." (P2) }\end{array}$ \\
\hline $\begin{array}{l}\text { SENTIMENTO, RELAÇÃO } \\
\text { E FELICIDADE }\end{array}$ & $\begin{array}{l}\text { "Tenho em mente que a sala de aula é um mundo cheio de mundinhos, e você tem que ser o gestor disso... E acho que é isso que } \\
\text { eu busco, o mais profundo sentimento do aluno, o reconhecimento dele... só obterei sucesso no momento em que vocês tiverem } \\
\text { sucesso." (P3) }\end{array}$ \\
\hline $\begin{array}{l}\text { TRANSMISSÃO, } \\
\text { CONHECIMENTO }\end{array}$ & $\begin{array}{l}\text { "Então, para mim, o ser educador, ele passa pela capacidade de fazer com que os alunos entendam o seu conteúdo... dei aula para } \\
\text { ensinar alguém e você aprendeu, depois adaptou. Isso é importante. Então, para mim, ser educador é isso: é medir o conhecimento } \\
\text { que o aluno consegue obter." (P4) }\end{array}$ \\
\hline $\begin{array}{l}\text { ENTREGA, RELAÇÃO, } \\
\text { ENERGIA E EMPATIA }\end{array}$ & $\begin{array}{l}\text { "Olha, ser docente é uma questão de entrega. A energia é muito forte porque há uma troca muito intensa com os teus alunos... A } \\
\text { docência não é uma coisa que você fica passivo... independente do método ou da ferramenta que você utilize numa disciplina, você } \\
\text { é um ser ali que você tá ativo... todo o tempo em sala de aula, porque você está em sala de aula tendo uma troca com o teus alunos. } \\
\text { Então essa entrega é muito forte, e as demandas são múltiplas e são distintas e são diferentes." (P5) }\end{array}$ \\
\hline
\end{tabular}

Fonte: Elaborado pelos autores. 
A escolha de trazer o significado que cada um dos professores entrevistados tem sobre ser docente faz sentido na medida em que se conecta com a fala de Nóvoa (2000). Conforme o autor, a formação da identidade docente é um processo pessoal e singular, longo e complexo que mescla o sentimento e o discurso de ser professor. As construções da identidade pessoal e profissional não estão dissociadas, mas são resultantes das relações tecidas consigo e com o social, entre o eu e o outro. Assim, no Quadro 1, retro, apresentam-se os fragmentos das narrativas dos professores que espelham o que significa ser docente para eles.

Diante da multiplicidade de significados, pode-se inferir que, para alguns professores, a docência ainda é basicamente uma transmissão de conhecimento e informação. Contudo, ressalta-se que a maioria dos professores que contribuíram com esta pesquisa vão além, veem-se como autores e demonstram consciência do seu papel enquanto profissionais da educação e "formadores" de outros profissionais.

Na narrativa de vida dos professores entrevistados, a humanização e a relação de troca com os alunos também representam um significado importante. A prática docente tem como natureza a participação no processo de humanização dos alunos, visando a contribuir para o desenvolvimento de conhecimentos, habilidades, atitudes e valores e buscando a inserção de uma consciência crítica e responsável da participação dos indivíduos na sociedade (PIMENTA, 2002).

“[...] então isso nos obriga também, enquanto educadores, a ter um cuidado, entender as demandas, não só as demandas legais dos projetos vinculados ao MEC, né? Mas as demandas humanas de cada aluno dentro do seu perfil e as necessidades que trazem pra cá, né? Eu acho que essa é uma questão, reforçando, muito importante, nós que temos que fazer, é um papel nosso [...], a gente precisa fazer com que as pessoas pensem e reflitam dentro das suas particularidades e limitações, e dar as condições pra esses alunos." (P5)

Além de formar cidadãos reflexivos, e com uma consciência social, sabe-se que um dos objetivos da universidade é preparar os indivíduos para o mercado de trabalho. De acordo com Confortin (2015), o professor, por meio da interação com o meio, e baseado no trabalho prático, necessita adquirir saberes a partir de experiências profissionais condizentes com o mercado profissional em que os alunos irão atuar, para que haja um compasso entre a teoria estudada e a prática. Esta se mostrou também uma preocupação dos docentes participantes da pesquisa e um dos motivos de sua própria realização pessoal. Um deles relata que recusou um convite para lecionar, afirmando que retornaria após ter adquirido "cheiro de estrada" (P2) e destacando sua 
preocupação em ter sabedoria e experiências para transmitir aos alunos. Nessa mesma visão, outro entrevistado relata:

“[...] uma das minhas preocupações e das metodologias que eu uso na aula é tentar fazer uma transição entre a teoria e a prática, eu acho que é aí que tá a lacuna, eu acho que é aí que tá a grande falha do ensino brasileiro, o aluno não consegue praticar a teoria e nem teorizar a prática, e isso eu não gosto, eu acho isso muito ruim, um boneco já não serve mais dentro de uma empresa." (P3)

As narrativas de histórias de vida expostas denotam sintonia com a fala de Nóvoa (2007). O autor ressalta que compreender como a pessoa do professor se formou é encontrar relações entre a pluralidade de suas trocas e vivências, sejam estas internas ou externas, nos diversos momentos de sua vida.

\section{Realização e reconhecimento}

Todos os entrevistados falam com orgulho e sentimento de realização e felicidade em ser docente. Segundo Catani et al. (2000, p. 168-169), "as memórias pessoalmente significantes são aquelas que carregam significados adquiridos em seus usos adaptativos, na maior parte das vezes, nas relações com os outros. Os outros são, desta forma, referências imprescindíveis das nossas lembranças”. Experiências vividas não desaparecem com a história do sujeito e cumprem um papel crucial na formação docente, mediante as imagens que se vão formando sobre o professor como profissional.

Assim, o professor denota sentimento de realização e reconhecimento na medida em que conecta seu "eu pessoa" com seu "eu profissional". Em outras palavras, isso acontece quando há um encontro entre o significado, os motivos que o levaram e as aprendizagens e trocas que realizou ao longo de sua vida. Durante as entrevistas, esse foi o momento em que mais observaram-se expressões de emoções e alegria. Tais percepções denotam a contribuição da metodologia de história de vida. Josso (1999) destaca que a história de vida possibilita ao pesquisador contatos com diferentes memórias, as quais se constituíram no desenvolvimento do indivíduo, tanto pessoal como profissionalmente. Além disso, permitem ao pesquisado o estabelecimento de um diálogo interior com seu próprio eu, de modo que ele próprio tome consciência sobre sua existência e compreenda, assim, sua trajetória de vida. Isso favorece uma produção de conhecimento que faça sentido para os propósitos da pesquisa e ao mesmo tempo para as pessoas entrevistadas. 
Destacam-se, a seguir, alguns trechos dessas narrativas que refletem o sentimento de realização e reconhecimento pela trajetória de docente:

“Eu vejo sementes que eu plantei. E a coisa que mais, mais me deixa feliz é quando eu vejo, o aluno tá lá. Ver antigos alunos sendo docentes, ou sendo profissionais bem-sucedidos. Foram sementes que eu ajudei a plantar. $\mathrm{O}$ carinho que te encontra assim quando você chega às vezes em lugares mais inusitados, e de repente tem alguém que te cumprimenta... e bah! E aquilo... isso aí algo que não tem preço.” (P2)

Então realização pra mim é isso, realmente sair $22 \mathrm{~h} 30$ da sala de aula contente por dar aula, por te dar uma boa aula, mas não eu achando que eu dei uma boa, mas eles me falando... os alunos me repassando, eles me dando o seu feedback... isso é gratificante. O reconhecimento vem naturalmente... vem o aluno, te convida pra ser paraninfo... a tua avaliação institucional é muito boa... (P4)

\section{Considerações finais}

A partir dos resultados obtidos pela análise das narrativas dos docentes participantes, pode-se compreender a sua constituição como professores ao longo de suas trajetórias. Algumas marcas foram mais significativas do que outras, às quais deu-se destaque e relevância. Além disso, foi possível compreender alguns quesitos-chave na formação da identidade docente, o que se mostrou altamente relevante para a pesquisa.

Com base na trajetória do grupo de professores aqui analisados, depreende-se que as influências familiares e de outros professores que cruzaram suas vidas são marcas constituintes dos movimentos construtivos da trajetória desses docentes. Nesse sentido, é possível considerar que as influências familiares são percebidas por grande parte dos docentes como fatores, em muitos casos, determinantes na constituição de suas carreiras pedagógicas.

Investigar a constituição docente em uma área que não prepara profissionais para a docência foi algo instigante. Ao aprofundar as narrativas da trajetória de vida de docentes, ficou clara a ausência de preparação pedagógica no início de suas vidas como professores. Desconhecimento esse que teve forte impacto nas principais dificuldades vivenciadas por esses profissionais em sala de aula: a leitura de turma, a relação de ensino e aprendizagem e a de professor e aluno. Nesse sentido, constata-se uma lacuna na formação de docentes do ensino superior. Ressalta-se a necessidade de se investir na dimensão pedagógica da docência, considerando-se os seguintes fatores: envolvimento em atividades e valores traduzidos em sensibilidade perante o aluno; valorização dos saberes da experiência; ênfase nas relações interpessoais; aprendizagem compartilhada; indissociabilidade entre teoria e prática. Igualmente, 
torna-se imperativo rever o papel da instituição e dos programas de pós-graduação (no que tange à formação de professores universitários) como possibilidade de desenvolver estratégias que envolvam empenhos pessoais e institucionais.

Dessa forma, a partir do diálogo com os referenciais teóricos que balizam este estudo, bem como com os apontamentos dos professores - sujeitos da pesquisa -, é importante destacar que a formação é um processo que se inicia muito antes do ingresso na carreira do magistério superior. Isso porque os professores consideraram em suas práticas cotidianas na universidade a influência das experiências anteriores ao acesso na carreira - escolares, familiares, profissionais e sociais.

As reflexões empreendidas ao longo deste trabalho permitem compreender a construção da identidade profissional como um processo constante, permanente e indissociável da identidade pessoal. As vivências e os aprendizados relacionados à história de vida se cruzam cotidianamente, permeados pela construção de sentidos e significados que tais cruzamentos permitem, entre eles os desejos de valorização profissional e de reconhecimento social.

Assim, as reflexões possíveis a partir dos dados de pesquisa corroboram a literatura que aponta os processos identitários docentes como resultado não apenas das experiências no campo do magistério, mas também das diversas dimensões que perpassam as trajetórias de vida desses sujeitos. Estes, em última instância, são aqueles que se apropriam das condições sociais disponíveis e criam as múltiplas possibilidades para o que é ser professor.

Ao valer-se da metodologia de história de vida, encontra-se mais uma importante contribuição deste trabalho. Essa escolha possibilita o acesso às referências que orientam os sujeitos em sua construção de significados, o desvelamento dos aspectos contextuais, relacionais e construtivos e, ainda, as influências da elaboração das suas identidades. Para os docentes das Ciências Sociais Aplicadas, área geralmente considerada mais técnica e instrumental, o uso da história de vida no estudo das trajetórias de vida de docentes é mais uma possibilidade de entrar em contato com a pessoa, deixando-a em conexão consigo e com sua vida. Concomitantemente à narração de suas histórias e trajetórias, percebeu-se a relação com as memórias e com a criação de sentidos e significados e, por consequência, como mais uma forma constituinte da identidade como professor universitário.

Por fim, acredita-se que as vivências dos professores, suas experiências pessoais e/ou profissionais, e os saberes que são mobilizados à medida que estes desenvolvem seu trabalho e, portanto, a história de vida, são fatores constituintes do processo de construção de suas identidades. E que essas histórias e identidades impactam as vidas dos acadêmicos e marcam esses alunos como pessoas e como profissionais.

Sabe-se que este não é um estudo findado em si mesmo, e que muito ainda precisa ser explorado nesse campo. Além disso, entende-se que o estudo tem algumas limitações, entre as quais está a amostra com um número limitado de participantes. Porém, a partir dos relatos obtidos, pode-se obter uma valiosa compreensão do papel da formação 
na construção da identidade docente. Como sugestões para estudos futuros, indica-se a aplicação da pesquisa para docentes de outras áreas de formação e com outras especialidades. Além disso, sugere-se a investigação de como a formação contribui para a identidade de professores no âmbito da educação básica, com professores escolares do ensino fundamental, médio, técnico e profissionalizante.

\section{Referências}

BARDIN, Laurence. Análise de conteúdo. São Paulo: Edições 70, 2000.

BURNIER, Suzana et al. Histórias de vida de professores: o caso da educação profissional. Revista Brasileira de Educação, v. 12, n. 35, p. 343-358, maio/ago, 2007.

BUSS, Andréia de Mello et al. Professores universitários narrando suas trajetórias docentes: em busca de marcas da vida e da profissão. In: CONGRESSO DE EDUCAÇÃO SUPERIOR, 9.; CONGRESSO DE EDUCAÇÃO, 8., 2008, Curitiba. Anais... Curitiba: PUCPR, 2008. v. 1. p. 10477-10489.

CARDoso, Maria I. S.; BATISTA, Paula M. F.; GRAÇA, Amândio B. S. A identidade do professor: desafios colocados pela globalização. Revista Brasileira de Educação, v. 21, n. 65, p. 371-390, abr./jun. 2016.

CATANI, Denice Barbara; BUENO, Belmira; SOUSA, Cyntia. O amor dos começos: por uma história das relações com a escola. Cadernos de Pesquisa, n. 111, p. 151-171, dez. 2000.

CELLARD, André. A análise documental. In: POUPART, J. et al. A pesquisa qualitativa: enfoques epistemológicos e metodológicos. Petrópolis, Vozes, 2008. p. 295-316.

DENZIN, Norman K. Interpretando as vidas de pessoas comuns: Sartre, Heidegger e Faulkner. Revista de Ciências Sociais, Rio de Janeiro, v. 27, n. 1, p. 29-43, 1984.

FÁVERO, Altair Alberto; MARQUES, Marta. Reflexão-ação no exercício da docência universitária. In: SEMINÁRIO DE PESQUISA EM EDUCAÇÃO DA REGIÃo SUL, 9., 2012, Caxias do Sul. Anais... Caxias do Sul: UCS, 2012. v. 1. p. 1-10.

FONSECA, Selva Guimarães. Saberes da experiência, histórias de vida e formação docente. In: CICILLINI, G. A.; NOGUEIRA, S. V. Educação escolar: políticas, saberes e práticas pedagógicas. Uberlândia: Edufu, 2002.

GIL, Antônio Carlos. Como elaborar projetos de pesquisa. São Paulo: Atlas, 2002.

JOSSO, Marie-Christine. História de vida e projeto: a história de vida como projeto e as "histórias de vida" a serviço de projetos. Educação e Pesquisa, v. 25, n. 2, p. 11-23, 1999.

NÓVOA, Antonio (Org.). Vidas de professores. 2. ed. Porto: Porto Editora, 2000.

NUNES, Dalma Persia Nelly Alves. A construção da docência universitária: a percepção dos professores no processo de socialização. ENCONTRO DE PESQUISA EM EDUCAÇÃO E CONGRESSO INTERNACIONAL DE TRABALHO DOCENTE E PROCESSOS EDUCATIVOS, Anais... 2013. v. 1. p. 30-41, 
PIMENTA. Selma Garrido (Org.). Saberes pedagógicos e atividade docente. 3. ed. São Paulo: Cortez, 2002.

QUADROS, Ana Luiza de et al. Os professores que tivemos e a formação da nossa identidade como docentes: um encontro com nossa memória. Ensaio - Pesquisa em Educação em Ciências, Belo Horizonte, v. 7, n. 1, p. 4-11, 2005.

RIBEIRO, Marinalva L.; CUNHA, Maria. I. Trajetórias da docência universitária em um programa de pós-graduação em Saúde Coletiva. Interface - Comunic., Saúde, Educ., v. 14, n. 32, p. 55-68, jan./mar. 2010.

RICHARDSON, Roberto Jarry. Pesquisa social: métodos e técnicas. 3. ed. São Paulo: Atlas, 2012.

TARDIF, Maurice. Saberes profissionais dos professores e conhecimentos universitários - elementos para uma epistemologia da prática profissional dos professores e suas consequências em relação à formação para o magistério. Revista Brasileira de Educação, n. 13, p. 5-14, jan./fev./abr., 2000.

. Saberes docentes e formação profissional. Petrópolis: Vozes, 2002.

TARDIF, Maurice; RAYMOND, Danielle. Saberes, tempo e aprendizagem do trabalho no magistério. Educação e Sociedade, Campinasm, Unicamp, v. 21, n. 73, dez. 2000.

TIMM, Edgar Zanini; ABRAHÃO, Maria Helena Menna Barreto. A história de vida na docência na Educação Superior e o desenvolvimento humano do professor. Revista de Educação do Cogeime, v. 24, n. 46, p. 123-143, 2015.

VIOLA, Juliana. Docência universitária: trajetórias e saberes da formação de professores na área de ciências biológicas da UFU. Horizonte Científico, v. 1, n. 1, p. 1-26, 2007.

ZABALZA, Miguel A. O ensino universitário: seu cenário e seus protagonistas. Porto Alegre: Artmed, 2004.

Recebido em: julho/2017

Aceito em: novembro/2017

\section{Endereço para correspondência:}

Av. Brasil Leste, 285 - São José

99052-900 Passo Fundo, RS, Brasil

<favero@upf.br> 